\title{
A SUPPLEMENT TO THE WORLD REVISION OF ODONTOMACHUS (HYMENOPTERA: FORMICIDAE) ${ }^{1}$
}

\author{
BY William L. BROWN, JR. \\ Department of Entomology \\ Cornell University \\ Ithaca, New York 14853
}

In a recent publication (Brown, 1976, Studia Entomologica 19: 67-171) I reviewed the world fauna of the ponerine ant genus Odontomachus. While that contribution was in press, and since its appearance, some significant new Odontomachus material, and information about material, has come to my notice. It seems appropriate to supplement the revision now, while it is fresh, by offering the new information for incorporation.

The first and most important addition is the description of a new (twentieth) species in the haematodus group.

Odontomachus scalptus new species

Holotype, worker: TL 10.0, HL 2.66, HW (across vertex) 1.79, ML 1.40, scape L 2.52, eye L 0.42, WL $3.08 \mathrm{~mm}$; CI 67, MI 53, SI 141.

Measurements for the 4 paratype workers range upward to the largest specimen, the antenna-less example from Oronoque R., Guyana: TL 11.0, HL 2.87, HW 2.05, ML 1.45, eye L 0.47 , WL $3.40 \mathrm{~mm}$; CI 71, MI 51 .

Closely resembling continental samples of $O$. bauri, but differing sharply in sculpture of mesonotum and gaster:

(1) Mesonotum and metanotum longitudinally striate, the striae tending slightly to diverge cephalad on mesonotum. In outline from side view, the mesonotum is a little more strongly convex than in bauri.

(2) First 3 gastric terga finely but very distinctly striate-punctulate, the punctulae in single longitudinal rows (striae) separating the very fine ridges (costulae). The punctulae tend to be more

\footnotetext{
${ }^{1}$ A Report of Research from the Cornell University Agricultural Experiment Station, New York State College of Agriculture and Life Sciences. The research was supported by National Science Foundation Grant GB-31662.

Manuscript received by the editor February 27, 1978.
} 
distinct anteriad on each segment, while the costulae predominate posteriad; this is especially true in the eastern (Surinam and Guyana) samples, in which the costulae become virtually obsolete on the anterior half of each tergum. The sculptured surface is opaque to sericeous-opaque, depending on magnification and lighting. The fourth gastric tergum, largely retracted, appears to be finely and superficially punctulate and subopaque. Underside of gaster shining, finely reticulate.

Other minor average differences from $O$. bauri are as follows: Costulae of the head and trunk a trifle more strongly shining (about 6-7 costulae per $0.1 \mathrm{~mm}$ square on each side of the vertexal midline). Striation of petiolar node finer than in most bauri, oblique. The node itself is a little less "dome-shaped", less convex in outline behind, and therefore more as in O. haematodus, but the metasternal process is low, and not produced into paired sharp teeth, as it is in O. haematodus.

Apical spine of petiole straight and only weakly back-tilted. Pilosity and pubescence copious and distributed much as in $O$. bauri, but on the average a trifle shorter and less dense; 4-8 standing hairs on pronotum; standing hairs of body about $0.2-0.45 \mathrm{~mm}$ long. Mesopleura obliquely striate, with a few coarse punctures in the mid-section; in the eastern samples, the mesopleural sculpture is effaced, smooth and shining in the mid-section, and the punctures here are smaller. Color black in Ecuadorean samples, with dark brown legs; antennal funiculi and tarsi yellowish-brown. Eastern samples dark reddish-brown to piceous (some possibly faded), funiculi and tarsi yellowish-brown. Palpi segmented 4,3.

In some specimens, the longitudinal striation of the metanotum even continues for a short distance onto the anterior part of the propodeum.

Queen and male unknown.

Holotype (Museum of Comparative Zoology at Harvard University, Cambridge, Massachusetts, USA) and one paratype worker from a rain forest litter berlesate taken $20 \mathrm{~km}$ south of Tena, Napo Prov., Ecuador, 11 July 1976, by S. and J. Peck, sample no. B-360. Two paratype workers from Surinam: [apparently near Paramaribo], "Sectie O," on forest floor, D. C. Geijskes, 15 July 1942. One paratype worker from southern Guyana: Oronoque River, $2^{\circ} 41^{\prime} \mathrm{N}, 25$ July 1936, by N. A. Weber, no. 594. Paratypes in MCZ and U.S. National Museum of Natural History, Washington, D.C. 
During work on the revision of Odontomachus (Brown, 1976, Stud. Ent. 19:67-171) I had in hand a single specimen of this new species, the paratype from Guyana listed above. The specimen lacked both antennae, and in a complex as difficult as the haematodus group, it was unwise to add yet another sibling species on the basis of a sample that might have been only a freak variant of $O$. bauri. Since the revision went to press, however, I have been able to study the 4 additional specimens from two widely separated hylaean localities, which convince me of the high probability that this phenon represents a distinct species.

In the key to neotropical Odontomachus species (Brown, 1976, op. cit., p. 112), O. scalptus keys uneasily to couplet 3, first lug (O. yucatecus) - "uneasily" because some $O$. scalptus samples have striation fairly distinct, even if "mixed", over the anterior half of gastric tergum I. O. scalptus differs primarily from $O$. yucatecus in having the gastric dorsum distinctly and sharply, if finely, sculptured.

The only other species with both mesonotum and gastric dorsum longitudinally striate is the sympatric $O$. caelatus, but this species is larger, has the gastric dorsum regularly striate (not punctulate), with a few, large, blunt hairs, and virtually obsolete pubescence. The appressed and decumbent pubescence of $O$. scalptus is abundant and conspicuous by contrast.

\section{Odontomachus turneri}

Dr. R. W. Taylor informs me in litt. that his recent researches in northern Queensland indicate that the variant of $O$. cephalotes having a densely punctulate or striate gastric dorsum and numerous standing hairs on the pronotum is actually a separate and distinct species occurring in the area near the base of Cape York and westward to Arnhem Land and beyond, perhaps to the Kimberleys. He finds it only in savanna or savanna woodland areas, and I recall that a form answering this general description is common nesting in termite hills in northern Queensland. Taylor writes that he has been calling this form $O$. turneri, but that it might possibly have a prior name (semicircularis Mayr?). I have thought of this form as corresponding to Forel's var. ajax, but since it shows considerable geographical variation, the whole situation needs re-study in the light of the new material now gathered in the Australian National Insect Collection. 


\section{Odontomachus laticeps}

In my discussion of this variable species in 1976 (p. $154 \mathrm{ff}$.), I found no South American records certainly attributable to it, but Dr. D. R. Smith has now called my attention to a small number of worker specimens in the U.S. National Museum from Bolivia that probably do belong to O. laticeps. These samples come from Covendo, Huachi and Cachuela Esperanza, all in Beni Province, and all were collected by W. M. Mann. These workers are brown in color, with legs usually lighter, and they all have the gastric dorsum predominantly finely but distinctly longitudinally striate and opaque; the bottoms of the striae are punctulate. The size is a little smaller than in Central American laticeps (HL 2.48, HW $1.67 \mathrm{~mm}$ in an average specimen from Huachi, Bolivia), but the cephalic index (67) is within the range of Central American laticeps, which have CI 66-73.

The main difference comes in the shape of the apical spine of the petiole: This is lower and thicker in side view in the Bolivian samples, but still sharply back-tilted: figure 14 (p. 156) in the 1976 rereview shows the slender spine of an average Central American specimen. The Bolivian population(s) could represent another sibling species of the haematodus group restricted to Bolivia (or even to the drainage of the Rio Beni), but the close relationship to $O$. laticeps is obvious, and I prefer to assign them to that species until we know more about the Bolivian Odontomachus in general. All previous records of $O$. laticeps from South America are based on O. biumbonatus or other species.

\section{Odontomachus mormo}

I described this giant species in the 1976 review (p. 161) from 3 specimens collected in transandean Ecuador. Now Stewart and Jarmila Peck have sent me more specimens, including a partial nest series with queen, from the Rio Palenque Research Station, $47 \mathrm{~km}$ SW of Santo Domingo de los Colorados, Pichincha Prov., Ecuador. The species remains known only from western Ecuador.

\section{Odontomachus bradleyi}

This species, also described in 1976 (p. 133) from Dept. Junin in central Peru, has now been rediscovered by the Pecks in eastern 
Ecuador: $23 \mathrm{~km} \mathrm{NE}$ of Baeza, Napo Prov., 4 March 1976, nest under $\log$ in pasture. This record is a long extension of range, and shows that the species is probably widely distributed along the eastern flank of the Andes in Amazonian-drainage valleys. 

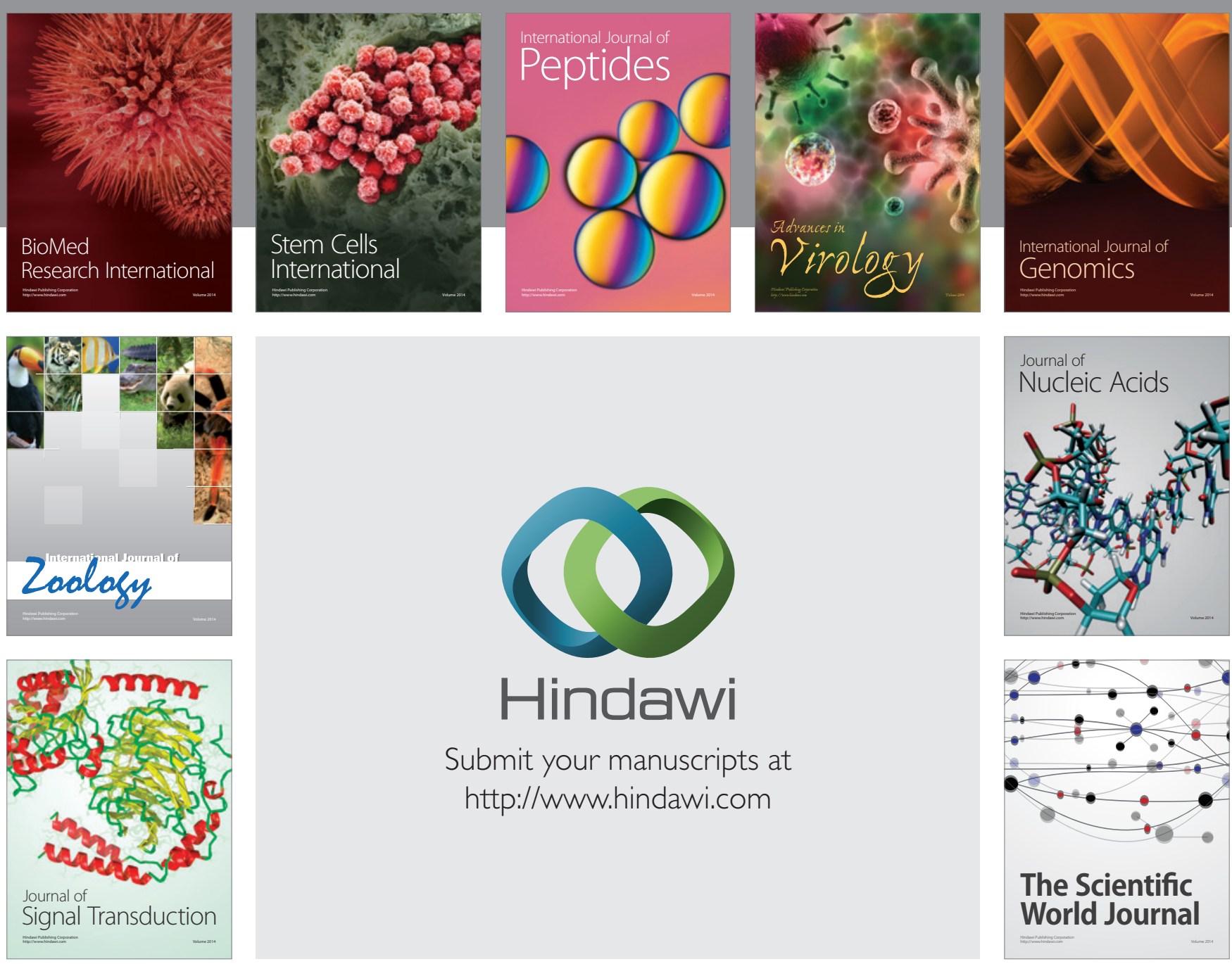

Submit your manuscripts at

http://www.hindawi.com
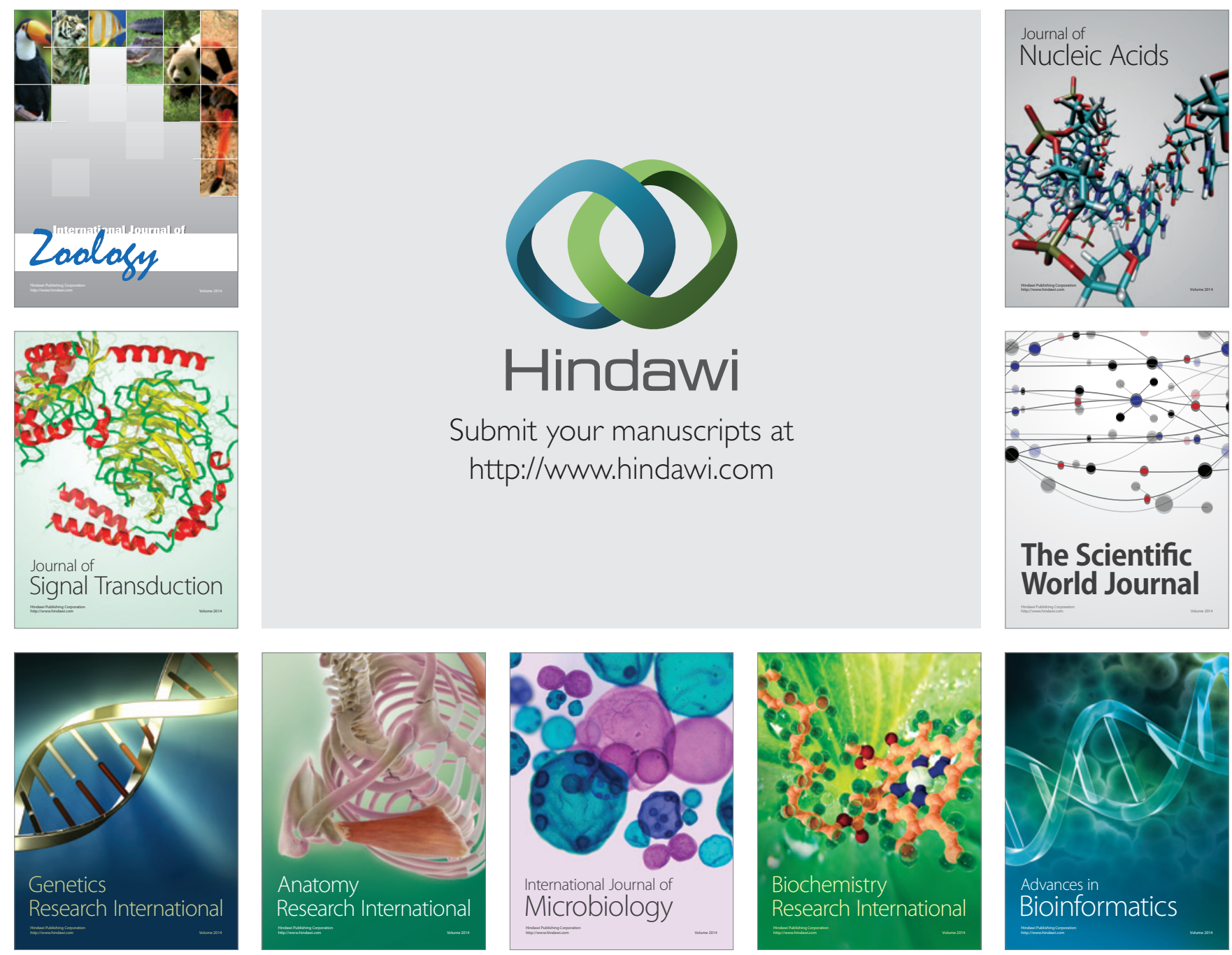

The Scientific World Journal
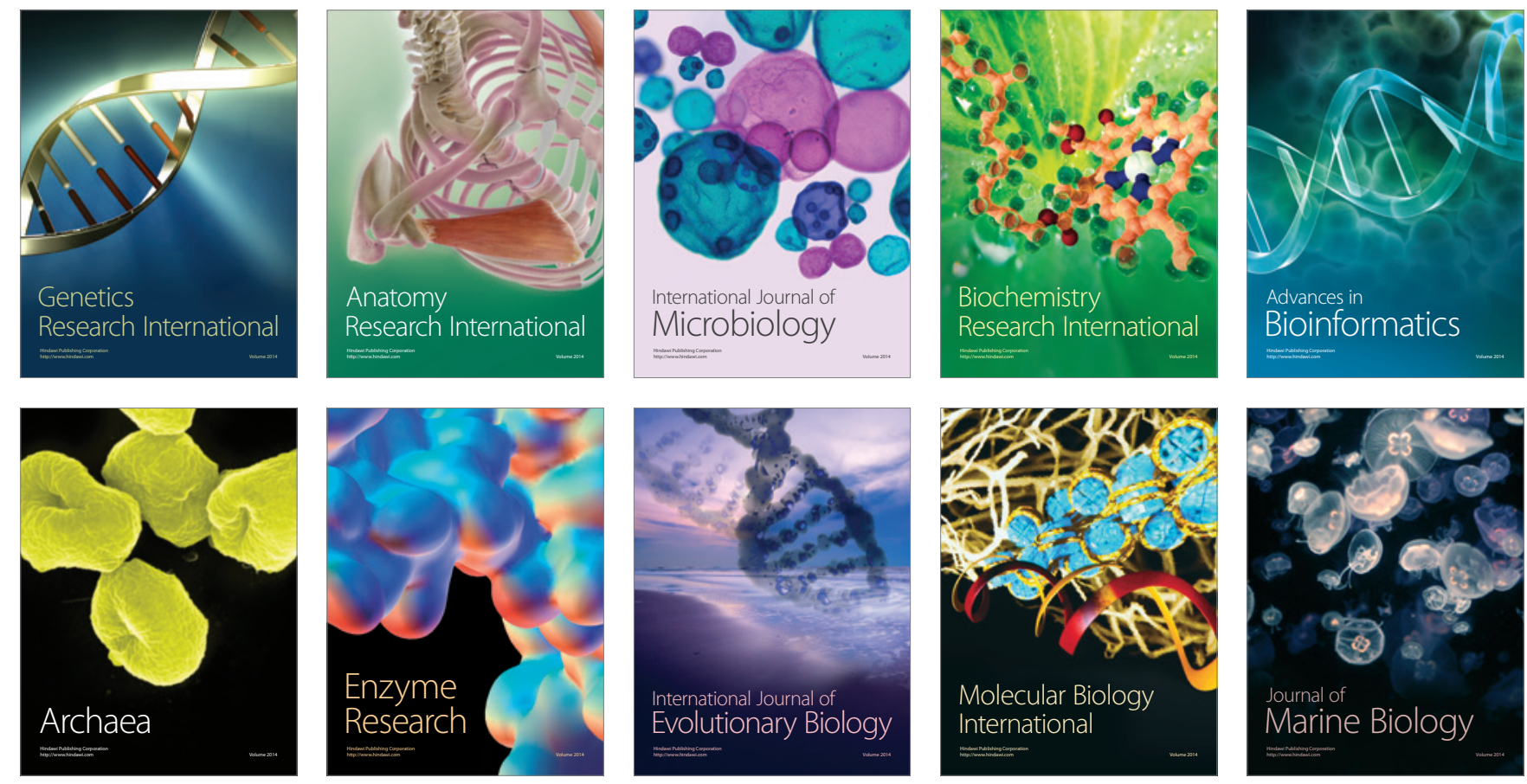